\title{
Understanding the anxiety and the needs of families helps to prevent medicolegal issues
}

\section{(1) Kazım Emre Karaşahin}

University of Health Sciences Turkey, Gülhane Faculty of Medicine, Department of Obstetrics and Gynecology, Ankara, Turkey

Date submitted:

23.12.2020

Date accepted:

25.12.2020

Online publication date: 15.06.2021

\section{Corresponding Author:}

Kazım Emre Karaşahin, M.D., Prof., University of Health Sciences

Turkey, Gülhane Faculty of Medicine, Department of Obstetrics and

Gynecology, Ankara, Turkey

ORCID:

orcid.org/0000-0002-4624-4874

Keywords: Violence, health care worker, doctor-patient relationship, workplace violence

\section{Dear Editor,}

It has been my pleasure to read the original article "Determination of the anxiety and the needs of family members of critical care patients in emergency departments" by Demirtas et al. (1) in a recent issue of Gülhane Medical Journal. In this article, the authors have addressed some important points that should be considered in the communication between the patient, carers, and healthcare staff. This argument would be valid in emergency facilities and other clinical settings, particularly in large and crowded health care facilities. In this context, a few more comments could support the findings presented in the article.

Demirtas et al. (1) mentioned that active listening skills during communication with patients and families, verbal and nonverbal, should be practiced by the healthcare staff. They also mentioned that this would improve the efficiency of healthcare provision and prevent some potential conflicts and medicolegal issues in the hospital setting.

Some preventable "professional, patient-related, organizational, and societal factors" have long been known to trigger episodes of violence. Many of them may be related-but not limited- to overloading of admissions, patient complexity, poor communication skills, reciprocal rudeness, stress, anxiety, language and cultural barriers (2).

While emergency departments, as well as most other settings, are "loud and crowded that cause anxiety to the patient and carers" (1), the role of environmental factors in the reduction of anxiety and violence has not been sufficiently evidenced so far (3). Thus, good communication seems crucial to prevent distress that leads to conflicts and potential medicolegal issues.

The authors' finding that communication was critically important, as mentioned by family members before physical comfort (1), is also supported by a previous article published by Kumari et al. (2), indicating improved communication combined with administrative support can help prevent most cases of violence. Law in Turkey and other countries discourages violence against medical staff. Moreover, any conflict between the two parts is just a waste of time and sources and has painful consequences that neither party desires. Therefore, preventing such conflicts should be the primary aim in all instances.

Finally, as an excellent clinical opinion, confirmed by more than 28 years of clinical experience, my suggestion is that, as concluded by Demirtas et al. (1), a healthy communication context must be met in patient-health care staff relations.

\section{Ethics}

Peer-review: Internally peer-reviewed.

Financial Disclosure: The author declared that this study received no financial support.

\footnotetext{
${ }^{\odot}$ Copyright 2021 by the University of Health Sciences Turkey, Gülhane Faculty of Medicine / Gülhane Medical Journal published by Galenos Publishing House.
} 


\section{References}

1. Demirtas A, Guvenc G, Aslan O, Oksuz E, Ucar AK. Determination of the anxiety and the needs of family members of critical care patients in emergency departments. Gulhane Med J. 2020;62:231-238.

2. Kumari A, Kaur T, Ranjan P, Chopra S, Sarkar S, Baitha $U$. Workplace violence against doctors: Characteristics, risk factors, and mitigation strategies. J Postgrad Med. 2020;66:149-154.

3. Vento S, Cainelli F, Vallone A. Violence against healthcare workers: a worldwide phenomenon with serious consequences. Front Public Health. 2020;8:570459. 